\title{
Hepatotoxicity of Pirimiphos-Methyl on Wistar Rats
}

\author{
Nosiri, C.I. , Okereke, S.C., Arunsi, U.O., Chujor, O.O., and \\ Nwaogwugwo, J.C.
}

Department of Biochemistry, Faculty of Biological and Physical Sciences, Abia State University, Uturu, Nigeria.

\begin{abstract}
Insect pests have caused a lot of menace to subsistence farmers especially those living in rural areas where there is limited access to agrochemicals. Owing to this, various classes of compounds have been synthesized by man to combat their concomitant threats. These chemicals directly target the organisms (insect pests) and indirectly pose health hazards to man by affecting major organs of the body when exposed inadvertently to them. One of such chemicals is pirimiphos-methyl. Pirimisphos-methyl, marketed as Actellic, is a phosphorothioate used to control insect pests in stored cereal grain, seeds and peanuts. However, the present study evaluated the hepatotoxicity of pirimiphos-methylon male and female wistarrats using standard analytical method to assay for the following parameters ALT, AST, ALP and total protein. Exactly twenty five (25) wistar rats were randomly divided into five (5) groups containing five (5) rats each. The result of the oral acute toxicity $\left(L D_{50}\right)$ showed mortality at highest dose of up to $2900 \mathrm{mg} / \mathrm{kg}$ with calculated $L D_{50}$ value of $2154 \mathrm{mg} / \mathrm{kg}$. The result of the biochemical analysis showed that the oral intake of pirimiphos-methyl caused a significant increase $(p<0.05)$ in alanine amino transferase $(A L T)$, aspartate amino transferase $(A S T)$ and alkaline phosphatase $(A L P)$. There was also a significant increase $(p<0.05)$ in the level of total protein between the control and the test groups. The result of histopathological studies revealed distortions in liver architecture with unevenly spaced portal triad around the central vein, moderate portal inflammation, severe ductular proliferation and fibrosis with the incomplete nodules transition to cirrhosis. Hence, the findings of this study indicated that the systemic use of pirimiphos-methyl could induce dose dependent biochemical and histopathological changes in the liver of wistar rats and therefore may be slightly toxic based on its LD50 result. Therefore, it is recommended that precautionary measures should be put in place during field application to circumvent possible adverse effects on consumers, who are increasingly being exposed to contamination from food and drinking water.
\end{abstract}

Keywords: Hepatic function, Hepatotoxicity, histopathology, Pirimiphos-methyl, Sub-acute toxicity.

\section{Introduction}

Food shortage due to pest infestation has remained a global problem over the last decades. The use of traditional methods in the storage of farm products by farmers who dwell in rural areas has led to wanton wastage of foods especially during the sowing period. This challenge has led to the introduction of pesticides in agriculture to salvage the destruction caused by pests. Pesticides as biologically active chemicals, which are applied on farmlands to control weeds, insects, fungi and other pests [1]. These compounds are toxic to nontarget species including humans [2]. The irrational and excessive use of pesticides play a crucial role in the occurrence of many diseases affecting plants, animals and human [3,4]. Pesticides have been implicated in various disorders and diseases including cancer, adverse reproductive outcomes, peripheral neuropathies, impaired immune functions and allergic sensitization reactions, particularly of the skin, cumulative inhibition of cholinesterase activity as a result of long-term low doses of exposure [5,6]. It has been reported that the toxicity of pesticides results in deleterious effects on many organs and systems in human and other mammals, particularly the nervous system [5], immune system [7], reproductive system and sexual hormones [8], liver [1], kidney [6], pancreas [5] and brain [6]. An alteration in biochemical parameters has been observed in experimental animals upon chronic exposure of pesticides. Included in the list are inhibition of both mammal brain and plasma cholinesterase activities [3], activity of liver functional enzymes including serum aspartate amino transferase (AST), alanine amino transferase (ALT), alkaline phosphatase (ALP) and lactate dehydrogenase [9,10], and increase in renal biochemical such as serum urea, uric acid and creatinine [11]. Also, alterations in histopathology of the liver, kidney and testes have been reported and these include mononuclear cell infiltration, enlargement of the veins and sinusoids, necrotic changes, cytoplasmic vacuolization, degeneration in nuclei of the liver, hepatocellular damage and damage in thyroid, parathyroid and adrenal glands $[10,8]$.

Pesticides are applied to grains during growth, post-harvest and storage in order to prevent pest infestation that could damage the crop integrity and affect harvest. One of such chemicals used in the control of insect pests is pirimiphos-methyl otherwise known as Actellics ${ }^{\circledR}$ which belongs to a group of compounds called 
organophosphates. It is used in the preservation of grains (beans) in Nigeria. The primary toxicity of organophosphate pesticides in acute exposure is cholinergic crisis that results from acetylcholinesterase inhibition [12,13]. This inhibition increases the availability of acetylcholine which in turn can stimulate cholinergic receptors producing both nicotinic and muscarinic effects in the organism such as muscle contraction and secretion in many glands [14]. Pirimiphos methyl has also been observed to affect proteolytic enzyme activities in rat heart, kidney, brain, and liver tissues [15]. It induces significant inhibition of brain and erythrocytes acetyl cholinesterase, plasma pseudo cholinesterase and non-specific carboxyl esterase of brain, plama and kidney [16]. The widespread use of pirimiphos methyl in agriculture and in public health drew our attention for its possible toxic actions in man and animals. However, the thrust of the present study was to investigate the hepatotoxicity of pirimiphos methyl on male and female wistar rats.

\section{Materials and Methods}

\subsection{Sample Collection and Preparation}

Pirimiphos methyl (Actellic) was bought from an Agrochemical Shop in Kaduna Central Market, Kaduna, Nigeria. The different concentrations of Pirimiphos-methyl were prepared. The Pirimiphos powder was measured using an AG and $\mathrm{G}$ electronic balance scale and different doses were prepared.

\subsection{Animals}

A total of 25 healthy wistar rats was procured from the laboratory animal unit of the Faculty of Veterinary Medicine, University of Nigeria, Nsukka and transported to the biochemistry laboratory of Abia State University, Uturu, Abia State, Nigeria were used for the study. The wistar rats were kept under normal standard environmental conditions of humidity ( 35 to $60 \%$ ), temperature $\left(25\right.$ to $28^{\circ} \mathrm{C}$ ) and a $12 \mathrm{~h} / 12 \mathrm{~h}$ light/darkness cycle and were fed adlibitum with standard feed and allowed free access to water. The wistar rats were allowed to acclimatize to laboratory conditions for two weeks before the commencement of the study. The wistar rats were handled in accordance with University ethical committee on animal handling.

\subsection{Acute toxicity test using Lorkes method [17].}

The wista rrats were randomly divided into three groups of 3 animals per group. Graded oral doses of pirimiphos-methyl $(10,100,1000 \mathrm{mg} / \mathrm{kg})$ were separately administered to the rats in each group in the first phase and 1600, 2900 and $5000 \mathrm{mg} / \mathrm{kg}$ used for the second phase. The control group was given distilled water. All the rats were allowed free access to food and water and were observed for a period of $24 \mathrm{~h}$ post-treatment for behavioural changes, signs of toxicity, and mortality.

\subsection{Sub-Acute toxicity study}

The albino rats were randomly divided into four groups of 5 rats per group. The rats were orally administered pirimiphos-methyl at doses of 10,20 , and $40 \mathrm{mg} / \mathrm{kg}$ daily for 14 days. The control group was given distilled water daily. The rats were weighed daily throughout the course of the experiment.

\subsection{Collection of blood and organ samples}

Fourteen days after daily administration of pirimiphos-methyl, the animals were fasted overnight, anaesthetized with chloroform and sacrificed. Blood samples were collected through cardiac puncture with the help of syringe and needle and dispensed into unheparinized containers for blood chemistry test and the liver carefully removed and kept in $10 \%$ formalin for histopathological studies.

\subsection{Procedures used for serum chemistry analysis}

Liver enzymes; alanine aminotransferase (ALT), aspartate aminotransferase (AST), and alkaline phosphatase (ALP) and total protein were spectrophotometrically determined using standard for the kits of Randox Laboratory Ltd, Co. Antrim, United Kingdom. The manufacturer's instructions for the entire biochemical test were strictly adhered to.

\subsection{Histopathological studies}

The liver was removed carefully and fixed in $10 \%$ formalin saline in labelled sample bottles after sacrificing the rats. The tissues were processed routinely and embedded in paraffin wax. Sections of $5 \mu \mathrm{m}$ thickness were cut and stained with haematoxylin and eosin.

\subsection{Statistical analysis}

Results were expressed as mean \pm SD (standard deviation). Statistical analysis was performed by Oneway analysis of variance (ANOVA) with the GraphPath Prism ${ }^{\circledR}$ Statistic software package, version 7.01. One- 
way ANOVA with a Turkey's multiple comparisons test was used to identify statistical differences among groups. A $p$-value of $<0.05$ was considered statistically significant.

\section{Results}

The result of the effect of pirimiphos methyl on the body weight of wistar rats post 14 days administration is presented in Table 1. The result revealed that the administration of pirimiphos methyl increased significantly the body weights of the rats in all the groups represented. The increase was in a dose dependent manner.

Table 1: Effect of pirimiphos methyl on the body weight of wistar rats post 14 days of administration

\begin{tabular}{|l|c|l|c|}
\hline & & Number of days & \\
\hline Animals & 0.00 & 7.00 & 14.00 \\
\hline Group 1 (Control) & $136.00 \pm 30.98$ & $151.00 \pm 26.82$ & $169.00 \pm 26.01$ \\
\hline Group 2 $(10 \mathrm{mg} / \mathrm{kg})$ & $121.00 \pm 38.93$ & $138.00 \pm 32.59$ & $152.00 \pm 35.84$ \\
\hline Group 3 $(20 \mathrm{mg} / \mathrm{kg})$ & $108.00 \pm 25.30$ & $129.00 \pm 21.32$ & $148.00 \pm 23.94$ \\
\hline Group $4(40 \mathrm{mg} / \mathrm{kg})$ & $172.50 \pm 52.98$ & $195.00 \pm 50.01$ & $212.00 \pm 48.94$ \\
\hline
\end{tabular}

The result of acute oral toxicity $\left(\mathrm{LD}_{50}\right)$ in rats showed that doses of pirimiphos methyl as high as $2,900 \mathrm{mg} / \mathrm{kg}$ body weight did cause behavioural change and $1 / 3$ mortality in the animals administered pirimiphos methyl (Table 2). The calculated $\mathrm{LD}_{50}$ was found to be $2154 \mathrm{mg} / \mathrm{kg}$ respectively.

Table 2: Determination of oral acute toxicity $\left(\mathrm{LD}_{50}\right)$ value of pirimiphos methyl

Phase I

\begin{tabular}{|l|l|l|l|}
\hline Group & Dose $(\mathrm{mg} / \mathrm{kg})$ & Death & Behavioral Pattern \\
\hline I & 10 & $0 / 3$ & Mouth scratching for a few minutes restlessness as usual \\
\hline II & 100 & $0 / 3$ & calm and healthy post 24h examination \\
\hline III & 1000 & $0 / 3$ & So calm, but agile after sometime \\
\hline
\end{tabular}

Phase 11

\begin{tabular}{|l|l|l|l|}
\hline Group & Dose $(\mathrm{mg} / \mathrm{kg})$ & Death & Behavioral Pattern \\
\hline I & 1600 & $0 / 1$ & Climbing on others \\
\hline II & 2900 & $1 / 1$ & Calm and aphrodisiac behavior and death \\
\hline III & 5000 & $1 / 1$ & Apnoe and death \\
\hline
\end{tabular}

$\mathrm{LD}_{50}$ is $2154 \mathrm{mg} / \mathrm{kg}$

The result of the effect of pirimiphos-methyl on total protein and liver enzymes of wistar rats is presented in Table 3.The result revealed that the oral administration of pirimiphos-methyl increased the serum concentration of Aspartate amino Transferase (AST). Groups $1(10 \mathrm{mg} / \mathrm{kg})$ and Group $2(20 \mathrm{mg} / \mathrm{kg}) \mathrm{had}$ the highest value of $33.67 \pm 0.58$ and $33.67 \pm 0.88$ respectively while the normal control group recorded a lower value of $26.00 \pm 1.00$. This revealed that there was a significant increase $(p<0.05)$ in the serum concentration of AST between the control and the test groups. Theresult showed that the oral administration of pirimiphos-methyl increased the concentration of Alanine amino Transferase (ALT) from 65.00 \pm 1.00 (Control) to 85.00 \pm 1.00 (Group 1). There was a fall in the serum concentration of ALT at higher dose (Group 2). The relative increase in the concentration of ALT was not statistically significant $(\mathrm{p}<0.05)$. The result also indicated that the oral administration of pirimiphos-methyl led to the rise in the serum concentration of Alkaline Phosphatase (ALP). The recorded value of ALP for the different groups were as follows: $72.24 \pm 0.55$ (control), $85.83 \pm 0.18$ (Group 1), 82.86 \pm 0.19 (Group 2) and 85.76 \pm 0.09 (Group 3). This implies that there was a significant increase $(\mathrm{p}<0.05)$ in the serum concentration of ALP between the control and the test groups. The result further revealed that the administration of pirimiphos-methyl slightly altered the serum level of total protein from $5.27 \pm 0.07$ (control) to $6.94 \pm 0.06$ (Group 3). The increase in the serum concentration of total protein was statistically significant $(\mathrm{p}<0.05)$ between the high and higher doses of pirimiphos-methyl.

Table 3: Effect of pirimiphos-methyl on total protein and liver enzymes of albino rats

\begin{tabular}{|l|l|l|l|l|}
\hline Test & Control & Group 1 $(10 \mathrm{mg} / \mathrm{kg})$ & Group 2 $(20 \mathrm{mg} / \mathrm{kg})$ & Group 3 $(40 \mathrm{mg} / \mathrm{kg})$ \\
\hline AST $(\mathrm{IU} / \mathrm{L})$ & $26.00 \pm 1.00^{\mathrm{a}}$ & $33.67 \pm 0.58^{\mathrm{c}}$ & $33.67 \pm 0.88^{\mathrm{c}}$ & $31.67 \pm 0.58^{\mathrm{b}}$ \\
\hline ALT (IU/L) & $65.00 \pm 1.00^{\mathrm{a}}$ & $85.00 \pm 1.00^{\mathrm{d}}$ & $55.33 \pm 1.53^{\mathrm{b}}$ & $70.00 \pm 1.00^{\mathrm{c}}$ \\
\hline ALP (IU/L) & $72.24 \pm 0.55^{\mathrm{a}}$ & $85.83 \pm 0.18^{\mathrm{c}}$ & $82.86 \pm 0.19^{\mathrm{b}}$ & $85.76 \pm 0.09^{\mathrm{c}}$ \\
\hline Total Protein $(\mathrm{mg} / \mathrm{dL})$ & $5.27 \pm 0.07^{\mathrm{a}}$ & $5.90 \pm 0.07^{\mathrm{a}}$ & $6.24 \pm 0.06^{\mathrm{a}}$ & $6.94 \pm 0.06^{\mathrm{b}}$ \\
\hline
\end{tabular}

Values represent the mean $\pm \mathrm{SD}$ for $\mathrm{N}=3$. Values in the same row bearing the same letter of alphabets are not significantly different from each other $(\mathrm{p}<0.05)$.

The histopathological examination of the liver (Fig. 1) of the wistar rats in all the treated doses of pirimiphos-methyl revealed alteration in the liver architecture, and this ranged from mild portal inflammation, 
moderate portal fibrosis, dustular formation, severe fibrosis with formation of incomplete nodules and transition to cirrhosis when compared with the control group.
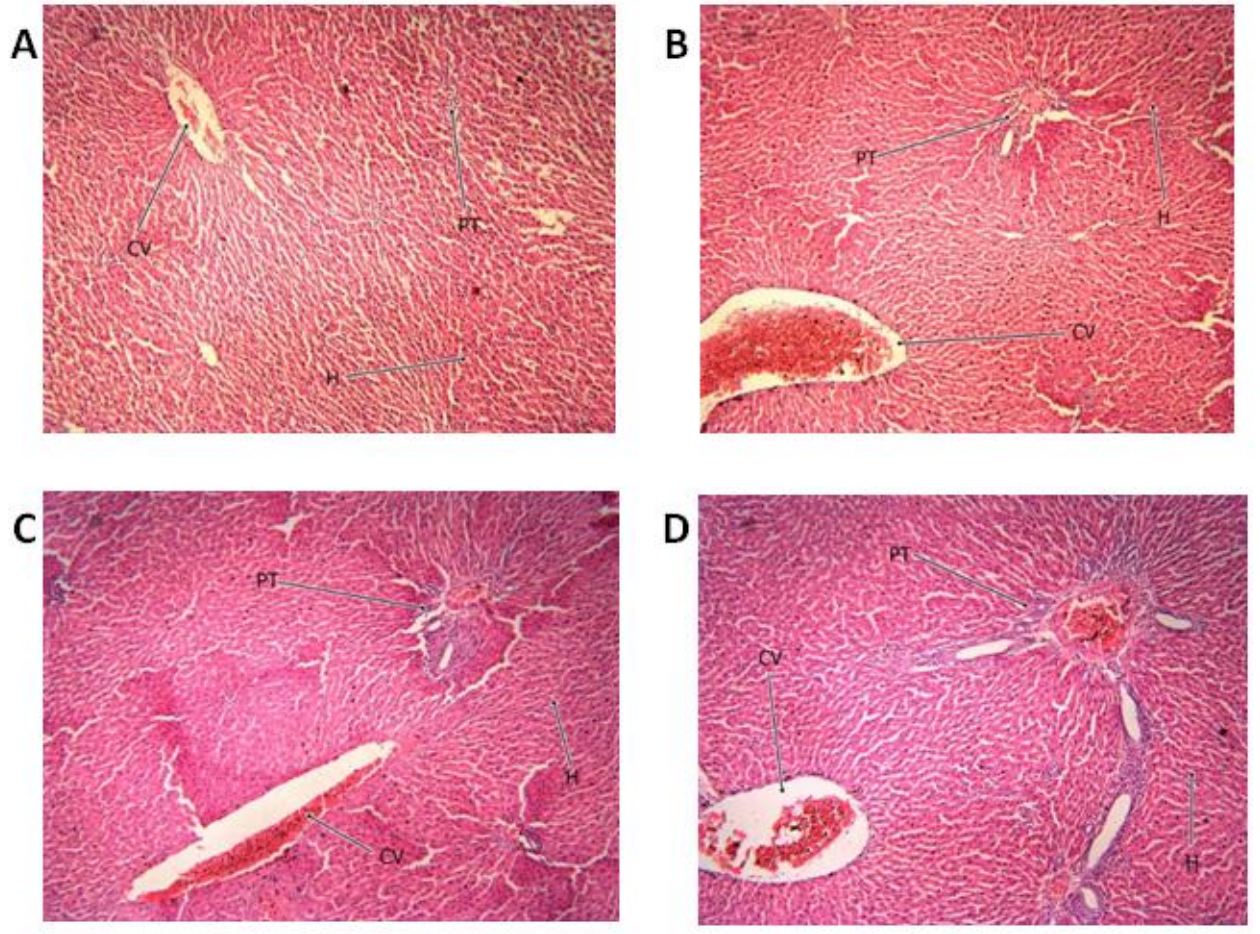

Plate A-D .Photomicrographs of the liver sections obtained from untreated (control) and treated wistar rats with various doses ofpirimiphos-methyl. Haematoxylin and eosin staining (H\&E), Magnification $(40 \times)$. (A) control, (B)wistar rats treated with $10 \mathrm{mg} / \mathrm{kg}$ of pirimiphos-methyl, (C) wistar rats treated with $20 \mathrm{mg} / \mathrm{kg}$ of pirimiphos-methyl(D), wistar rats treated with $40 \mathrm{mg} / \mathrm{kg}$ of pirimiphos-methyl showing PT Portal triad, HP- Hepatocyte, CV-Central vein

\section{Discussion}

The irrational and excessive use of pesticides to preserve and increase the shelf-life of agricultural products has posed a lot of environmental hazards to plants, animals and human. Pesticides over the years have been greatly implicated in various disorders and diseases including cancer, peripheral neuropathies, impaired immune functions and allergic sensitization reactions, particularly of the skin, as a result of long-term low doses of exposure [5, 6]. Owing to the toxicity of these pesticides, especially pirimiphos-methyl to non-target organism (human), the present study was aimed at investigating the hepatotoxicity of pirimiphos-methyl on male and female wistar rats. The result showed that the administration of pirimiphos-methyl caused a significant increase in the body weights due to the increased feed consumption of the experimental animals. Hypothalamus participates in the control of appetite as the lateral nuclei serve as the feeding centre which when stimulated causes hyperphagia [18]. This hyperphagia may be related to the effects of the active principle (PM) on the central structures involved in the control of feed intake. Reports have linked hyperphagia with lesions of the ventromedian nucleus of the hypothalamus. It could then be suggested that PM may have stimulated this centre thus increasing the feed intake and consequently the body weight gain observed in the work [19, 20, 21]. The result of the acute toxicity study showed mortality at highest dose of up to $2900 \mathrm{mg} / \mathrm{kg}$ indicating that the $\mathrm{LD}_{50}$ of pirimiphos methyl is $2154 \mathrm{mg} / \mathrm{kg}$. This shows that pirimiphos methyl is not safe for oral usage and according to Organization for Economic Cooperative and Development (OECD) standard for ranking toxic substances [22], any substance whose $\mathrm{LD}_{50}$ is greater than $500 \mathrm{mg} / \mathrm{kg}$ and less than $5000 \mathrm{mg} / \mathrm{kg}$ can be ranked under category 4 of the OECD guidelines for acute toxicity and can be said to be slightly toxic if swallowed [23].

The liver is regarded as the central hub of metabolism. It is a principal organ in the metabolism of carbohydrate, lipid and protein. Alteration in the architecture of the liver cells could result in the release of certain indicator enzymes in the body. The liver functional transaminases (AST and ALT) and alkaline phosphatase (ALP) enzyme activity in serum are most frequently measured for diagnosis of liver diseases particularly infective hepatitis, alcoholic cirrhosis, biliary obstruction and hepatocarcinoma [3, 24]. It has been reported that the normal levels of the former liver functional enzymes activity are up to 37 IU/L for AST, 41 IU/L for ALT and 68-400IU/L for ALP in healthy individual rat sera [25, 26]. 
The results of the biochemical analysis showed that the oral administration of pirimiphos methyl cause an exceptional rise only in alanine amino transferase in the serum of treated experimental rats (Table 3). The slight increase in the levels of the liver marker enzymes (AST, ALT and ALP) following oral administration of pirimiphos methyl may have resulted from the leakage of these enzymes into the circulation, which may be attributed to damage in the structural integrity of the liver [27] especially ALT which is specifically found more in the liver. Plasma levels of ALT and AST have been shown to be important parameters in the diagnosis of liver damage $[28,29]$. The result shows that there was significant increase $(p<0.05)$ in the serum concentration of aspartate amino transferase (AST) between the control and the test groups. This increase was statistically significant $(\mathrm{p}<0.05)$ at $10 \mathrm{mg} / \mathrm{kg}$ of pirimiphos methyl. This implies that the exposure of the experimental rats to pirimiphos methyl may have resulted in damage to the hepatocytes (liver cells).

The result also reveals that the post administration of pirimiphos methyl on the experimental animals led to a significant increase in the serum concentration of ALT. This increase was notsignificant in a dose dependent manner. Animals that received $10 \mathrm{mg} / \mathrm{kg}$ of the pirimiphos methyl had the highest level of ALT. This implies that the pesticide, pirimiphos methyl is hepatotoxic at lower doses. ALT is mostly used as a specific indicator of hepatic injury that represents a marker of hepatocellular necrosis [30]. This high level of ALT activity shows that the cells of the liver may have been inflamed or undergone cell death. As the cells are damaged, the ALT leaks into the blood stream leading to a rise in serum levels. In another study, it was reported that treatment with dimethoate at $75 \mathrm{mg} / \mathrm{kg}$ for 28 days caused significant increase in activity of AST and ALT [31].

The activity of Alkaline phosphatase increased significantly $(\mathrm{p}<0.05)$ post administration of the pirimiphos-methyl dose when compared with the control group. The experimental animals that were given the high dose of $10 \mathrm{mg} / \mathrm{kg}$ body weight recorded the highest value with mean and standard deviation of $85.83 \pm 0.18$ IU/L.Plasma alkaline phosphatase is known to increase as a result of biliary obstruction as seen in cholestatic disease of the liver. These findings are in line with the earlier work of a researcher who reported that the activity levels of GOT and GPT were significantly increased by carbonfuran pesticides for 16 days [32]. In another study, it was also observed that 300 and $600 \mathrm{mg} / \mathrm{kg}$ per day carbendazim affected the liver parameters [33]. The significant increase in the liver enzymes: ALT, AST and ALP is in agreement with findings of several studies that reported the deterioration of liver enzymes as a result of exposure to pesticides $[34,35]$.

The result further revealed that the administration of pirimiphos-methyl slightly altered the serum level of total protein. The concentration of this biochemical parameter was highest in group 3 and lowest in the control with means and standard deviations of $6.94 \pm 0.06$ and 5.27 \pm 0.07 respectively. The significant increase in the total protein may be indicative of reduced catabolism in the liver.The hispathological examination result in this study demonstrated that the 14-day post administration of pirimiphos-methyl at highest dose of $40 \mathrm{mg} / \mathrm{kg}$ body weight resulted in distortion of liver architecture (Fig.1). The result showed that the portal triads were unevenly spaced around a central vein and there were moderate portal inflammation, severe ductular proliferation and severe fibrosis with formation of incomplete nodules and transition to cirrhosis. The findings implies that the injection of pirimiphos-methyl is toxic to target and non-target organisms. These findings are in agreement with the work of Selmanoglu and Akay [36] who reported similar histopathological changes including mononuclear cell infiltration, congestion, hydropic degeneration and hepatocellular damage in the liver of male rats treated with dimethoate, endosulfan and carbaryl.

\section{Conclusion}

The result of the current study indicated that pirimiphos-methyl induced some biochemical and histopathological changes in the liver of exposed wistar rats. According to these results, it is suggested that systemic pesticides exposure might cause hazardous effects; especially at high doses to non-target organisms, including humans. However, precautionary measures should be put in place during field application to circumvent possible adverse effects on consumers, who are increasingly being exposed to contamination from food and drinking water.

\section{References}

[1]. M.A.E.El-Sayed, H.F. Abdel-Razik,, R. Gamal,andM.F.Hany, Biochemical and histopathological effects of systemic pesticides on some functional organs of male albino rats,Journal of Applied Sciences Research, 8(11), 2012, 5459-5469.

[2]. N.K.Rajawat, I.Soni, andP.Mathur,Hepatotoxicity of cyfluthrin after acute exposure in Swiss albino mice,Bulletin of Environment, Pharmacology and Life Science, 4(2), 2015, 128-134.

[3]. S.A.M.Zaahkouk, E.G.E.Helal, T.E.I.Abd-Rabo, and S.Z.A.Rashed,Carbamate toxicity and protective effect of vitamin A and vitamin $\mathrm{E}$ on some biochemical aspects of male albino rats, The Egyptian Journal of Hospital Medicine, 1, 2000, 60-77.

[4]. M. Al-Haj, A.Nasser, and A.Anis,Survey of pesticides used in qat cultivation in DhaleandYafeand their adverse effects, Journal of Natural and Applied Sciences, 9(1), 2005, 103-110.

[5]. H.H.Hagar and A.H.Fahmy, A biochemical, histochemical and ultrastructural evaluation of the effect of dimethoate intoxication on rat pancreas,Toxicology Letters, 133, 2002, 161-170.

[6]. F.A. Khogali, J.B.Sheikh, S.Abdel, A.Rahman, A.Rahim, and M.H.Daghestani,Histopathological and hematological effects of dimethoate40EC on some organs of albino mice, J. King Saud Univ., 18(2), 2005, 73-87. 
[7]. N.M. Aly, and K.S.El-Gend,Effect of dimethoate on the immune system of female mice,Journal of Environmental Science and Health, 35(1), 2000, 77-86.

[8]. I. Muthuviveganandavel, P.Muthuraman, S. Muthu, and K. Srikumar, Individual and combined biochemical and histological effect of Cypermethrin and Carbendazim in male albino rats,Journal of Applied PharmaceuticalScience, 1(9), 2011, $121-129$.

[9]. G. Begum, Carbofuran insecticide induced biochemical alterations in liver and muscle tissues of the fish (Clariasbatrachus.Linn) and recovery response,Aquatic Toxicology,66, 2004, 83-92.

[10]. F. Sayim,Dimethoate-induced biochemical and histopathological changes in the liver of rat,Experimental and Toxicological Pathology, 59, 2007 237-243.

[11]. H.Soufy, M.K.Soliman, E.M. El-Manakhly,andA.Y.Gaafar, Some biochemical and pathological Investigations on Monosex Tilapia following chronic exposure to carbofuranpesticide, GlobalVeterinaria, 1(1), 2007, 45-52.

[12]. C.N. Pope, Organophosphorous pesticides: do they all have the same mechanism of toxicity? Journal of Toxicology, Environment and Health Part B Critical Reviews, 2, 1999, 161-181.

[13]. G. Cabello, M. Valenzuela and A. Vilava, A rat mammary Tunor Model Induced by the Organo-phosphorous pesticides Parathion and Malathion, possibly through Acetyl-cholinesterase inhibition. Environmental Health Perspectives, 109(5), 2001, $471-479$

[14]. P. Taylor, Anticholinesterase agents. In: G.A. Goodman, T.W. Rall, A.S. Nies, and P. Taylor, editors. The pharmacological Basis of therapeutics. New-York: Pergamon Press Inc; 1990. pp. 131-147.

[15]. D. Mantle, M. Saleem, F. Williams, R. Wilkins, and A. Shakoori, Effect of pirimiphos methyl on proteolytic enzyme activities in rat heart, kidney, brain and liver tissues in vivo, ClinicaChimicaActa, 27, 262(1-2), 1997, 89-97.

[16]. P. Rajini, Muralidhara, and M. Krishnakumari, Inhibitory pattern of tissues esterase in rats fed dietary pirimisphos methyl. Journal of Environmental Science and Health Part B, 24(5), 1989, 509-524.

[17]. D.A. Lorke,A new approach to practical acute toxicity testing. Archives of Toxicology, 54, 1983, $275-287$.

[18]. C.Nosiri, J.Anuka, and A. Rafindadi, Endosulfan induced polydypsia in adult wistar rats. The Internet Journal of Pharmacology, 9(1) 2009 .

[19]. A. Psychoyos, La reproduction, In: P. Meyer ed., PhysiologieHumaine, Paris: Flammarion Médecine-Sciences; 1983, 471-493.

[20]. S.I. Fox, Human physiology, Sixth edition, Boston: Mc. Graw-Hill; 1999, 612-614.

[21]. W.F. Ganong, Physiologiemedicale, Paris: Masson, 2001, 408-411.

[22]. OECD, Guideline document on acute toxicity, Environmental Health and Safety Monograph Series on Testing and Assessment No. 24, 2000.

[23]. E.Schlede, U.Mischke, W.Diener, and D.Kayser,The international validation study of the acute-toxic-category method (oral),Archives of Toxicology,69, 1995, 659-670.

[24]. M.A. Abdel-Wahhab, M.M., Abdel-Galil, A.M. Hassan, S.H., Hassan, S.S. Nada,A. Saeed, and M.M. El-Sayed,Zizyphusspinachristi extract protects against aflatoxin B1-intitiated hepatic carcinogenicity, African Journal of Traditional, Complementary and Alternative Medicine, 4(3), 2007, 248-256

[25]. R.K.Murray, D.K. Granner, P.A. Mayes, and V.W. Rodwell, Harper's Biochemistry, $16^{\text {th }}$ edition, $1991,681$.

[26]. J. Kaneko, W. Haevey, and L. Bruss, Clinical Biochemistry of Domestic Animals. $5^{\text {th }}$ ed., Academic Press, Inc. San Diego, London, New York, 1997

[27]. H.M.Bilgin, M.Atmaca, B.D.Obay, S.Ozekinci, E.Tasdemir, and A.Ketani,, Protective effects of coumarin and coumarin derivatives against carbon tetrachloride-induced acute hepatotoxicity in rats,Experimental Toxicology and Pathology, 63, 2011, $325-332$.

[28]. E.M.Williamson, D.T.Okpako, and F.J. Evans, Selection, preparation and pharmacological evaluation of plant material, England, UK: Wiley, 1996

[29]. J. Renugadevi, and SM.Prabu, Cadmium-induced hepatotoxicity in rats and the protective effect of naringenin,Experimental Toxicology and Pathology, 62, 2010, 171-181.

[30]. V. Deepak, M.D. Gopal, R. Hugo, M.D. Rosen,Abnormal findings on liver function tests: interpreting result to narrow the diagnosis and establish a prognosis,Postgraduate Medicine, 107(2), 2000, 100-114.

[31]. A.M. Attia, and H.M.Nasr,Dimethoate-induced changes in biochemical parameters of experimental rat serum and its neutralization by black seed (Nigella Sativa L.) oil,Slovak Journal of Animal Science, 42(2), 2009, 87-94.

[32]. E.M.A. Abu Zeid, The effect of carbofuran and endosulfan on the African Catfish, Clariasgarieplnus, doctoral diss., University of Putra, Malaysia,2001.

[33]. G. Selmanoglu, and M.TAkay,Histopathological effects of the pesticide combinations on liver, kidney and testis of male albino rats, Pesticides, 15, 2000, 253-262.

[34]. T.M. Farahat, G.M.Abdelrasoul, M.M. Amr, M.M. Shebl, F.M. Farahat, and W.K. Anger, Neurobehavioural effects among workers occupationally exposed to organophosphorous pesticides. Occupational and Environmental Medicine, 60(4), 2003, 279-86.

[35]. J.A. Patil and A.J. Patil, Biochemical effects of various pesticides on sprayers of grape gardens. Indian J ClinBiochem, 18(2), $2003,16-22 . b v$

[36]. G. Selmanoglu, N.Barlas, S.Songur, and E.A.Kocskaya,Carbendazim-induced heamatological, biochemical and histopathological changes to the liver and kidney of male rats,Human Experimental Toxicology, 20 (12), 2001, 625-630. 